\title{
Curcumin induces cell death without oligonucleosomal DNA fragmen- tation in quiescent and proliferating human CD8+ cells
}

\author{
Adriana Magalska, Agnieszka Brzezinska, Anna Bielak-Zmijewska, \\ Katarzyna Piwocka, Grażyna Mosieniak and Ewa Sikora ${ }^{\bowtie}$ \\ Laboratory of Molecular Bases of Aging, Nencki Institute of Experimental Biology, Warszawa, Poland; \\ 凶e-mail: e.sikora@nencki.gov.pl
}

Received: 30 June, 2006; revised: 01 August, 2006; accepted: 21 August, 2006

available on-line: 02 September, 2006

\begin{abstract}
Cytotoxic CD8+ cells play an important role in determining host response to tumor, thus chemotherapy is potentially dangerous as it may lead to $T$ cells depletion. The purpose of this study was to elucidate the propensity of quiescent and proliferating human CD8+ cells to undergo cell death upon treatment with curcumin, a natural dye in Phase I of clinical trials as a prospective chemopreventive agent. Methods: We treated human quiescent or proliferating CD8+ cells with $50 \mu \mathrm{M}$ curcumin or irradiated them with UVC. Cell death symptoms such as decreased cell viability, chromatin condensation, activation of caspase-3 and specific DFF40/CAD endonuclease and oligonucleosomal DNA fragmentation were analyzed using MTT test, microscopic observation, Western blotting and flow cytometry. Results: Curcumin decreased cell viability, activated caspase- 3 and decreased the level of DFF45/ICAD, the inhibitor of the DFF40/CAD endonuclease. However, this did not lead to oligonucleosomal DNA degradation. In contrast, UVC-irradiated proliferating, but not quiescent CD8+ cells revealed molecular and morphological changes characteristic for apoptosis, including oligonucleosomal DNA fragmentation. Curcumin can induce cell death in normal human lymphocytes both quiescent and proliferating, without oligonucleosomal DNA degradation which is considered as a main hallmark of apoptotic cell death. Taking into account the role of CD8+ cells in tumor response, their depletion during chemotherapy could be particularly undesirable.
\end{abstract}

Keywords: CD8+, cell death, curcumin, DNA degradation

\section{INTRODUCTION}

Apoptosis, or programmed cell death, is a fundamental process essential for both development and maintenance of tissue homeostasis (reviewed in Jacobson et al., 1997). Cells undergoing apoptosis exhibit specific morphological changes including membrane blebbing, cytoplasmic and chromatin condensation, DNA fragmentation, nuclear breakdown and assembly of membrane-enclosed vesicles termed apoptotic bodies, eventually subjected to phagocytosis (reviewed in Wyllie et al., 1980). Multiple apoptotic stimuli trigger the activation of proteases called caspases, which in turn initiate and execute the apoptotic program (reviewed in Riedl
\& Shi, 2004). One of the hallmarks of the terminal stages of apoptosis is oligonucleosomal DNA fragmentation (Wyllie et al., 1980). Recent years have led to the discovery of two major apoptotic nucleases, termed DNA fragmentation factor (DFF) or caspaseactivated DNase (CAD) and endonuclease G (Endo G). In non-apoptotic cells, DFF exists in the nucleus as a heterodimer, composed of a $45 \mathrm{kDa}$ chaperone and inhibitory subunit (DFF45 or ICAD-L) and a 40 kDa latent nuclease subunit (DFF40/CAD). Apoptotic activation of caspase- 3 or -7 results in the cleavage of DFF45/ICAD and release of the DFF40/CAD nuclease which then forms active homo-oligomers (reviewed in Widlak \& Garrard, 2005).

Abbreviations: 7-AAD, 7-aminoactinomycin D; AICD, activation-induced cell death; APCs, antigen presenting cells; CAD, casapase-activated DNase; CFSE, carboxyfluorescein diacetate succinimidyl ester; DFF, DNA fragmentation factor; Endo G, endonuclease G; FCS, fetal calf serum; HA, host antigen; mAb, monoclonal antibody; MDR, multidrug resistance; MTT, 3-(4,5-dimethyldiazol-2-yl)-2,5-diphenyl tetrazolium bromide; PBS, phosphate-buffered saline; PHA, phytohaemagglutinin; TCR, T-cell receptor. 
Human lymphocytes undergo so called "activation-induced cell death" (AICD) when activated lymphocytes are induced to die during the downphase of their immune response. This is caused by ligation of the Fas receptor (CD95) with Fas ligand (CD95-L) whose expression is up regulated by TCR activation (Krammer, 2000). AICD can be mimicked in vitro by stimulation of TCR with non-specific mitogen, phytohaemagglutinin (PHA), or by specific stimulation of TCR/CD28 with anti CD3/antiCD28. A second type of physiological cell death of $\mathrm{T}$ cells caused by deprivation of survival stimuli, such as cytokines, leading to down-regulation of anti-apoptotic proteins such as Bcl-2 can be called "passive cell death" (Akbar \& Salmon, 1997).

Moreover, normal lymphocytes can undergo cell death induced by drugs as a side-effect of chemotherapy aimed at malignant cells. This type of lymphocyte cell death can be included in the category of damage-induced cell death (De Martinis et al., 2005). Usually chemotherapy causes severe toxicity in normal tissues, leading to side-effects such as mucosistis, hair loss, and myelosuppression. In addition, chemotherapy induces acute lymphopenia and chronic depletion of $\mathrm{T}$ cells, leading to increased susceptibility to opportunistic infections.

CD8+ cells play a very important role in the anti-tumor immune response. Antigens from peripheral tumor cells can enter the class I pathway for presentation by host antigen (HA) presenting cells (APCs) to CD8 cells, a process commonly known as "cross-presentation" (Heath \& Carbone, 2001). It has recently been shown in mice that not only the tumor presence but also induction of tumor cell apoptosis in vivo increases tumor antigen cross-presentation of $\mathrm{HA}$ to $\mathrm{CD} 8$ cells which are not deleted but primed as was revealed by CFSE proliferation assay (Nowak et al., 2003). Quantitation of lymphocyte populations in the peripheral blood of patients enrolled in multiagent dose-intensive regiments revealed significant lymphocyte depletion, but with a more profound effect on CD4+ than on CD8+ T-cells (Mackall, 2000). Accordingly, in this paper we checked interested whether CD8+ cells, both quiescent and activated, might be indeed resistant to apoptosis induced by a classical DNA damaging agent, UVC, and the natural dye curcu$\min$.

Curcumin (diferuloyl methane) is a naturally occurring yellow pigment derived from the rhizome of Curcuma longa. Turmeric or curcuma, the powdered form of the rhizome, is widely used in Asian countries where this plant has been cultivated for centuries. Curcumin exhibits a variety of pharmacological effects including anti-inflammatory, antiinfectious and anticancer activities (Lin et al., 2000). The exposure of populations worldwide to curcu- min, and its many uses, has led to studies aimed at elucidating some of its activities with particular attention on the anticancer activity. These flourished with several Phase I human trials that have shown this compound to be well tolerated (Cheng et al., 2001; Hsu et al., 2002; Iqbal et al., 2003; Sharma et al., 2004).

It has been shown that curcumin can inhibit proliferation and/or induce cell death in in vitro experiments with different cancer cells. The most common cell death mode upon curcumin treatment seems to be apoptosis (reviewed in Lin et al., 2000; Karunagaran et al., 2005). There are also reports showing that unlike in cancer cells, curcumin does not induce apoptosis in normal cells (Jiang et al., 1996). However, we showed that curcumin induced cell death not only in cancer but also in normal rat and human lymphocytes (Bielak-Zmijewska et al., 2000). The cell death induced with curcumin in normal and transformed lymphocytes was not characterized oligonucleosomal DNA fragmentation that is typical for apoptosis. Moreover, we showed in Jurkat cells that curcumin induced caspase- 3 activation and following DFF40/CAD activation but concomitantly blocked the active centre of the endonuclease thus precluding DNA fragmentation (Sikora et al., 2006). Here we investigated whether also in normal human quiescent and proliferating lymphocytes curcumin gives the same symptoms, namely cell death with activation of caspase-3 and DFF40/CAD endonuclease but without oligonucleosomal DNA fragmentation. As the oligonucleosomal DNA degradation is considered a main hallmark of apoptotic cell death the lack of this sort of degradation can be improperly interpreted as an absence of apoptosis.

\section{MATERIALS AND METHODS}

T-cell preparation and treatment. Mononuclear cells were obtained by standard centrifugation over Ficoll-Paque from lymphocyte buffy coat (about $10^{8}$ cells) of peripheral blood of eight healthy blood donors (aged 22-33 years). The buffy coats were obtained from the Regional Centre for Blood Donation and Blood Treatment in Warsaw (Poland). All cell cultures were conducted in RPMI 1640 supplemented with $10 \%$ FCS, $2 \mathrm{mM}$ L-glutamine and antibiotics, at a starting density of $0.8 \times 10^{6} \mathrm{cells} / \mathrm{ml}$. The cells were stimulated by PHA $(5 \mu \mathrm{g} / \mu \mathrm{l})$ added at the time of seeding (day 0 ). From day 3 on, $60 \mathrm{U} / \mathrm{ml}$ recombinant IL-2 (rIL-2; Peprotech EC LTD, UK) was added every 2-3 days. CD8+ cells from day 0 and day 10-14 were isolated by MACS-magnetic cell sorting (Miltenyi Biotec, Medianus, Poland) by positive selection. The purity was $>97 \%$ and cell viability measured by trypan blue exclusion test was over $95 \%$. 
To induce apoptosis with curcumin, CD8+ cells were treated for $8 \mathrm{~h}$ with $50 \mu \mathrm{M}$ dye (Merck, Warsaw, Poland). For UVC treatment cells were irradiated with a pulse of ultraviolet light of $254 \mathrm{~nm}$ and an energy output of $100 \mathrm{~J} / \mathrm{m}^{2}$ using a Stratalinker 2400 (Stratagene, La Jolla, CA, USA) and collected $6 \mathrm{~h}$ after irradiation.

Cell phenotyping. Phenotypes of cells were examined by standard flow cytometry procedures. This involved double immunofluorescence staining of blood samples using Simultest from BecktonDickinson. Each experiment included cells incubated with isotype controls. Samples were analyzed on FACSCalibur (Becton-Dickinson, Warsaw, Poland) using Cell-Quest software (Becton-Dickinson).

Cell proliferation assay. Mononuclear lymphocytes were labelled with a tracker dye, carboxyfluorescein diacetate succinimidyl ester (CFSE, Molecular Probes) according to Hasbold et al. (1999), before stimulation with PHA and then at the 1st and 7th day of cell culture as described previously (Brzezinska et al., 2003; 2004; Brzezinska, 2005).

DNA content analysis by flow cytometry. Cells were analyzed for DNA content by flow cytometry. One million cells were collected, washed and suspended in Nicoletti buffer $(0.1 \%$ sodium citrate, $\mathrm{pH} 7.4,0.1 \%$ Triton X-100, and $50 \mu \mathrm{g} / \mathrm{ml}$ propidium iodide). DNA content was determined on a flow cytometer (FACSCalibur, Becton Dickinson). The sub- $G_{1}$ fraction represents apoptotic cells; cellular debris was excluded from the analysis. The levels of apoptotic cells induced in specific experimental conditions were calculated according to the following formula: (percentage of induced apoptosis minus percentage of spontaneous apoptosis $) /(100$ minus percentage of spontaneous apoptosis) $\times 100$.

Cell viability measurement. Cell viability was measured by MTT (3-(4,5-dimethyldiazol-2-yl)2,5-diphenyl tetrazolium bromide; Sigma) assay as described by the manufacturer.

Spontaneous apoptosis was measured using 7-AAD (7-amino-actinomycin D; Calbiochem) which stains apoptotic and necrotic cells. The 7-AAD positive cells were analyzed by flow cytometry.

Cell morphology observation. Morphological observation was performed after Hoechst 33258 staining (Molecular Probes, Eugene, OR, USA). Cells $\left(0.2-0.3 \times 10^{6}\right)$ were centrifuged on cytospin, fixed with $70 \%$ ethanol, washed in PBS and stained for 10 min in $1 \mu \mathrm{M}$ Hoechst 33258 dye. Samples were visualized by epifluorescence microscopy (Nicon) and images were acquired with a color CCD camera.

Caspase- 3 activation measurement. The activation of caspase- 3 was analyzed by flow cytometry using PE-conjugated anti-active caspase-3 mAb (BD Pharmingen) according to the manufacturer's protocol.
Western blotting. The protocol used for Western blotting has been reported (Bielak-Mijewska et al., 2004).

Proteins (40 $\mu \mathrm{g}$ per lane) were separated on $12 \%$ PAGE/SDS and electrotrasferred onto nitrocellulose membrane (Hybond-C, Amersham). Membranes were probed overnight at $4{ }^{\circ} \mathrm{C}$ with rabbit polyclonal anti-DFF40 (1:500), anti-DFF45 (1:500), or mouse monoclonal anti-PARP-1 (1:500) (BD Biosciences). Specific proteins were visualized with horseradish peroxidase-conjugated anti-IgG antibodies and the enhanced chemiluminescence (ECL) reagent (Amersham Pharmacia).

Statistics. Statistical analysis was performed by using Student's $t$-test.

\section{RESULTS}

\section{PHA induces cell to proliferation and cell death}

The majority of human lymphocytes isolated from peripheral blood are in a quiescent state. They can be stimulated to proliferate in culture by mitogens and IL-2. Upon stimulation with PHA, which mimics pathogen activation, $\mathrm{T}$ cells undergo intense proliferation and then activation-induced cell death (AICD). The most intense proliferation and AICD of $\mathrm{T}$ cells were observed at the 7th day following PHA stimulation (Fig. 1A). After 10 days of culture, proliferation was still at a high level; almost $70 \%$ of live cells were proliferating as measured by CFSE assay. Also morphological observation indicated that the majority of cells on day 10-14 of culture were blasts (Fig. 2B). The percentage of dying cells measured by 7 -AAD staining accounted for about $20 \%$ at the 5th day after stimulation and lasted at that level to the 14th day of culture, but afterwards it increased dramatically to about $80 \%$ in four-week-old cultures (Fig. 1B). As the 7-AAD assay does not discriminate between apoptotic and necrotic cell death, we checked cell DNA content by using propidium iodide to measure the sub- $G_{1}$ fraction corresponding apoptotic cells. The sub- $\mathrm{G}_{1}$ fraction was relatively high (about 30\%) at 5 days after PHA stimulation and practically absent in two-week-old cultures reaching again $20 \%$ at the end of culture (4 weeks) (Fig. 1B).

During the initial days of culture the proportion of cytotoxic and helper cells changed, namely the CD8+ population increased from about $20 \%$ on day 0 to about $60 \%$ on day 14 suggesting that CD8+ cells might be less prone to PHA-induced cell death than CD4+ cells (Fig. 1C).

Accordingly, for further experiments isolated CD8+ cells from day 10-14 of mononuclear lym- 
A

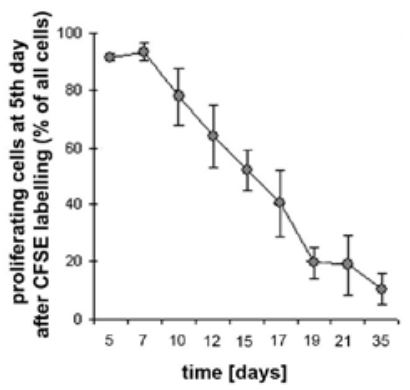

B

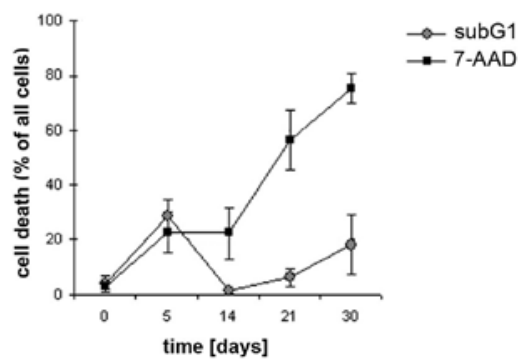

C

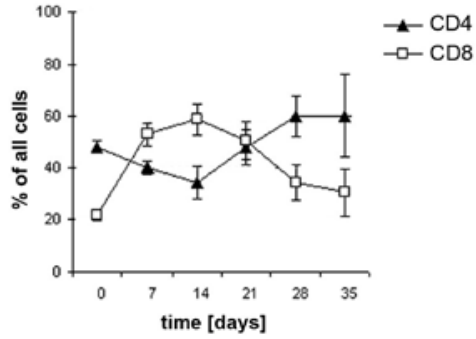

Figure 1. Proliferation, cell death and phenotype of PHA-stimulated $\mathrm{T}$ cells in long term culture of mononuclear lymphocytes.

A. Proliferation assay was performed by cell staining with CFSE and fluorescence was measured at 5th day after staining only in the gate of live cells (7-AAD negative). B. The amount of dying cells was assessed by 7-AAD staining and DNA content was measured with propidium iodide (sub- $G_{1}$ fraction). C. Cells were phenotyped using Simultest. Data are expressed as mean \pm S.D. of eight independent experiments.

phocyte culture were chosen as they predominate in culture during the period of the more intense proliferation and they display the lowest ratio of the cell death. CD8+ cells activated stimulated after isolation from the mononuclear fraction did not respond with proliferation (not shown).

\section{UVC but not curcumin induces DNA fragmentation} in CD8+ cells

As previously we showed that rat and human quiescent $\mathrm{T}$ cells are less prone to undergo cell death induced by UVC than proliferating lymphocytes (Radziszewska et al., 1999; 2000; Piwocka et al., 1999) now we decided to study this difference in more detailed by focusing on UVC and curcumin's impact on non-activated and activated purified CD8+ cells.
A

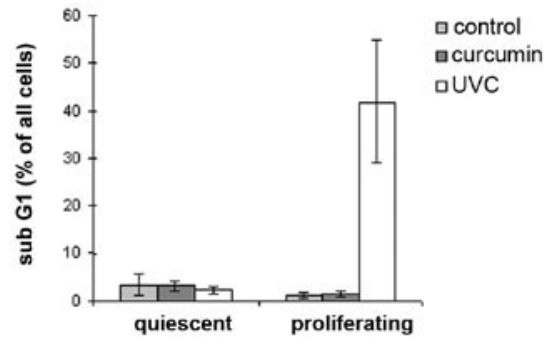

B
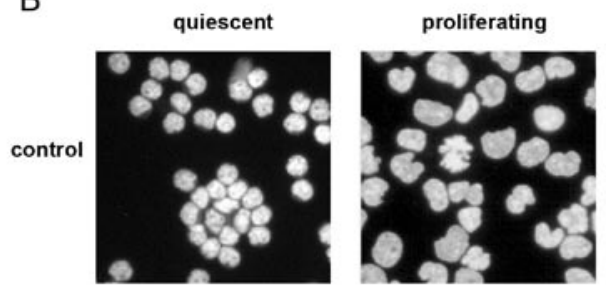

uvc
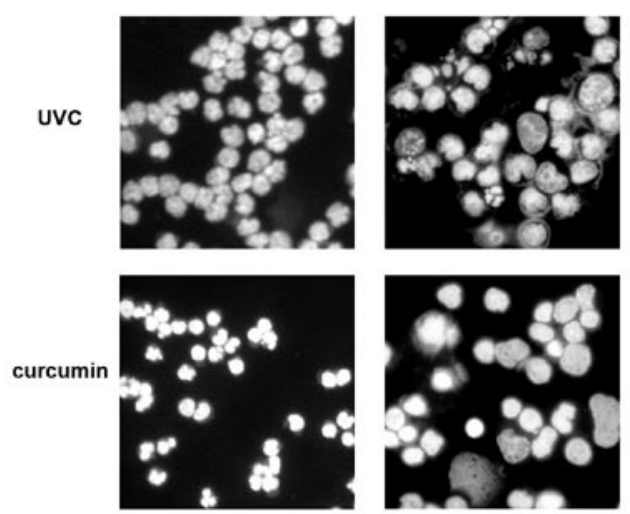

Figure 2. DNA fragmentation (A) and chromatin condensation (B) in quiescent and proliferating CD8+ cells treated with curcumin or UVC-irradiated.

DNA fragmentation was assessed by flow cytometry (sub$G_{1}$ ). Data are expressed as mean \pm S.D. of three independent experiments. Chromatin condensation was observed microscopically after staining of cells with Hoechst 33258. Representative pictures of three independent experiments are shown.

To this end, CD8+ cells either isolated directly from non-stimulated peripheral lymphocytes (quiescent) or from cultured mononuclear human lymphocytes stimulated with PHA in vitro and cultured for 10-14 days (proliferating) were irradiated with UVC and analyzed $6 \mathrm{~h}$ later or treated with curcumin for $8 \mathrm{~h}$. We chose $50 \mu \mathrm{M}$ concentration of curcumin which had earlier been found to induce in human $\mathrm{T}$ cells and Jurkat cells the mode of cell death without oligonucleosomal DNA degradation (Piwocka et al., 1999; Bielak-Zmijewska et al., 2000; Sikora et al., 2006).

Data presented in Fig. 2A show that $6 \mathrm{~h}$ after UVC irradiation more that $40 \%$ of proliferating CD8+ cells revealed significant DNA fragmentation and were present in the sub- $G_{1}$ fraction. However, the sub- $\mathrm{G}_{1}$ fraction of curcumin-treated cells did not exceed $5 \%$ in either quiescent or proliferating cells. Similarly only a few percent of quiescent UVC-treat- 
ed cells were found in the sub- $G_{1}$ subpopulation (Fig. 2A).

Apoptotic chromatin condensation temporally correlates with DNA fragmentation and frequently its efficiency depends on the degree of internucleosomal cleavage (Widlak et al., 2003). Thus, we have analyzed nuclear morphology of CD8+ cells treated with curcumin or UVC-irradiated (Fig. 2B). Only proliferating UVC-irradiated cells revealed characteristic chromatin condensation and fragmentation as well as formation of apoptotic bodies resembling typical apoptosis, which could be expected from DNA content analysis. Quiescent CD8+ cells after UVC irradiation seemed to be quite healthy. Curcumin treatment resulted in chromatin condensation in almost all cells, quiescent or proliferating. However, unlike in UVC-irradiated proliferating cells, no apoptotic bodies were seen (Fig. 2B).

\section{Curcumin induces caspase-3 activation followed by cleavage of its substrates}

In the majority of apoptotic cells oligonucleosomal DNA degradation results from the activity of endonuclease DFF40/CAD. The nuclease is activated upon caspase-3-catalyzed cleavage of its inhibitor DFF45/ICAD (Enari et al., 1998; Halenbeck et al., 1998; Liu et al., 1998). Thus, one could conclude from the results shown above that curcumin, in contrast to UVC, did not induce caspase- 3 activation. To verify this assumption the presence of activated caspase- 3 was analyzed in curcumin-treated or UVC-irradiated $\mathrm{CD} 8+$ either quiescent or proliferating cells using
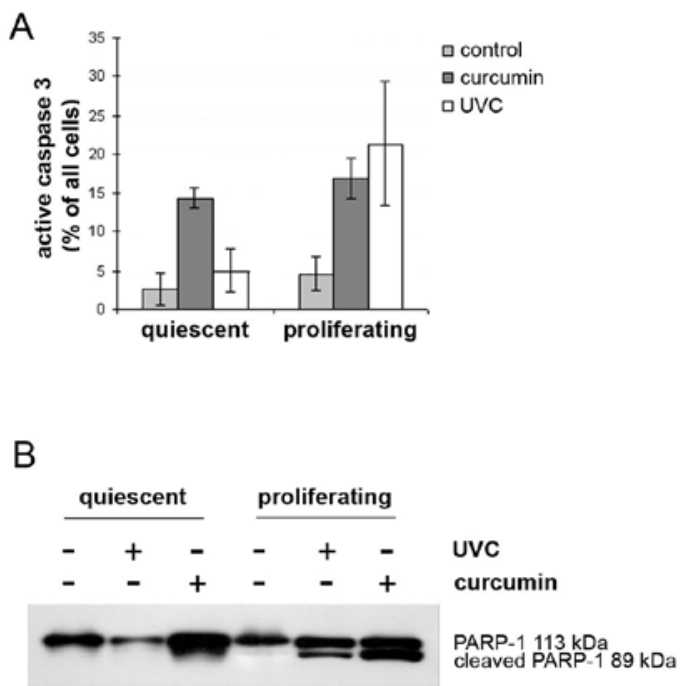

Figure 3. Active caspase- 3 in quiescent and proliferating CD8+ cells at $8 \mathrm{~h}$ after treatment with $50 \mu \mathrm{M}$ curcumin.

(A) The number of cells that contained active form of caspase- 3 was measured by flow cytometry and results are expressed as mean \pm S.D. of three independent experiments. (B) The truncated form of PARP-1 was assessed in whole cell lysates by Western blotting. A representative blot of three independent experiments is shown.

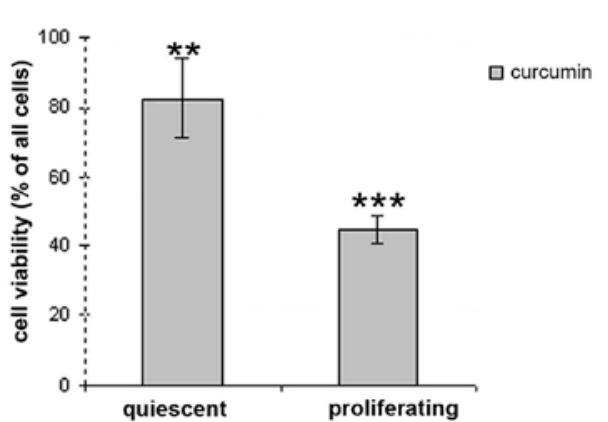

Figure 4. Viability of quiescent and proliferating CD8+ cells after treatment with $50 \mu \mathrm{M}$ curcumin.

Cell viability was measured after $8 \mathrm{~h}$ of curcumin treatment by the MTT assay (values are in the relation to untreated control). Data are expressed as mean \pm S.D. of three independent experiments. ${ }^{* *}, P \leq 0.001 ;{ }^{* *}, P \leq 0.0001$.

flow cytometry (Fig. 3A). As expected the analysis revealed the presence of active caspase- 3 in proliferating, but not quiescent CD8+ cells irradiated with UVC. Moreover, active caspase-3 was detected also in curcumin-treated cells, both quiescent and proliferating. The activity of caspase- 3 was assessed in the same cells by detection of the $89 \mathrm{kDa}$ fragment of PARP-1, which is a specific product of caspase-3 activity (Fig. 3B). The truncated form of PARP-1 could be detected in proliferating CD8+, both irradiated with UVC and treated with curcumin, as well as in quiescent curcumin-treated cells. Using MTT assay we showed that the percentage of survivals accounted for slightly more than $40 \%$ and $80 \%$ in curcumintreated proliferating and quiescent cells, respectively (Fig. 4). These data show that in terms of survival, the impact of curcumin is stronger on proliferating than on quiescent CD8+ cells.

\section{Curcumin induces degradation of DFF45/ICAD that leads to formation of the potentially active DFF40/ CAD nuclease in CD8+ cells}

In healthy non-apoptotic cells, the DFF40/ CAD nuclease exists in the nucleus as a heterodim-

A

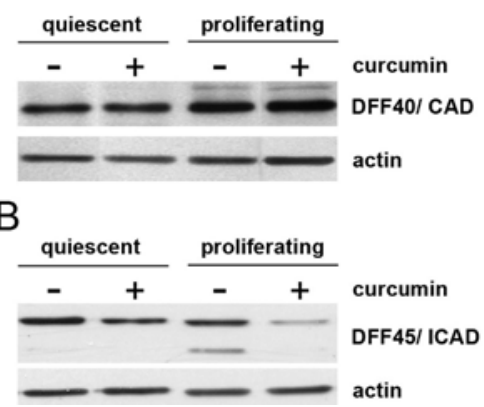

Figure 5. Levels of DFF subunits in CD8+ cells after $8 \mathrm{~h}$ of treatment with $50 \mu \mathrm{M}$ curcumin.

DFF40/CAD (A) and DFF45/ICAD (B) were assessed by Western blotting in whole cells lysates. The representative blots of three independent experiments are shown. 
er with its inhibitor DFF45/ICAD (a 35-kDa splicing variant of DFF45-DFF35/ICAD-S-resides in the cytoplasm). Activation of caspase-3 results in the cleavage of DFF45/ICAD and release of DFF40/ CAD, which forms active homo-oligomers (Liu et al., 1999; Widlak et al., 2003; Woo et al., 2004). Here we show that DFF40/CAD is present in CD8+ cells, and its total level remains essentially unchanged in cells treated with UVC or curcumin as measured by Western blotting in whole cell lysates (Fig. 5A). In a marked contrast to the level of DFF40/CAD, the level of DFF45/ICAD decreased in curcumin-treated CD8+ cells, the decrease being less pronounced in quiescent cells than in proliferating ones (Fig. 5B). It is of note, that in quiescent CD8+ cells, the band of DFF35 was not present, but in proliferating cells, as expected, its disappearance was proportional to the decrease of the DFF45 band.

\section{DISCUSSION}

There are many facets to cancer prevention and one of them is using natural or synthetic compounds allowing suppression, retardation or inversion of carcinogenesis. Only a few such agents have been used to date in the clinic and these include non-steroidal anti-inflammatory drugs for colon, finasteride for prostate, and tamoxifen or reloxifene for breast tumors. An ideal chemopreventive agent should restore normal growth control to preneoplastic or cancerous cells by modifying aberrant signalling pathways or inducing cell death in cells beyond repair. The characteristics of such an agent include selectivity for transformed cells and more than one mechanism of action to foil the redundancy or crosstalk in signalling pathways (Manson et al., 2005). It seems that curcumin fits this picture very well by affecting many signalling pathways, it is able to induce cell death in any tested cancer cells like leukaemia, melanoma, breast, lung, prostate, colon, renal, hepatocellular and ovarian carcinomas (reviewed in Karunagaran et al., 2005), including those resistant to apoptosis due to the multidrug resistance phenotype (MDR) (Bielak-Mijewska et al., 2004).

It appears from the available data that curcumin impact on cancer cells can be explained by its pleiotropic activity and many targets in the cell like COX-2 (Goel et al., 2001; Shishodia et al., 2003), HO-1 (Balogun et al., 2003) or v-Src (Leu et al., 2003). On the other hand, the multitiude of curcumin's targets can also be explained by its influence on transcription regulation. Curcumin has been shown to inhibit the AP-1 transcription factor which is involved in apoptotic program and regulation of cell proliferation of many cells (Sikora et al., 1997; Bharti et al., 2004; Zheng et al., 2004). Also NF- $\kappa B$ involved in pro-survival and apoptotic pathways is inhibited by curcumin (Deeb et al., 2003; 2004). Recently curcumin has been shown to repress histone acetyltransferase-dependent chromatin transcription by inhibiting its p300/CREB-binding protein (Balasubramanyam et al., 2004). p300 is a ubiquitously expressed global transcriptional coactivator that has a critical role in a wide variety of cellular phenomena including cell cycle control, differentiation and apoptosis (Giordano \& Avantaggiati, 1999).

An open question is the curcumin's selectivity for transformed cells; alas, the data regarding curcumin impact on normal cells are rather scarce. Previously we showed that curcumin induced cell death in rat splenocytes as well as in human quiescent and proliferating $\mathrm{T}$ cells, but the cell death mode in terms of chromatin degradation and oligonucleosomal DNA fragmentation did not resemble typical apoptosis (Bielak-Zmijewska et al., 2000). Also others described cell death in human $\mathrm{V} \gamma 9 \mathrm{~V} \Delta 2 \mathrm{~T}$ cells caused by curcumin, due to high molecular mass, but not oligonucleosomal DNA degradation (Cipriani et al., 2001). Recently, the Gautam's group (Gao et al., 2004) published data of an immunomodulatory activity of curcumin, namely its suppression of lymphocyte proliferation, development of cell-mediated cytotoxicity and cytokine production in vitro. Although curcumin at $30 \mu \mathrm{M}$ concentration irreversibly inhibited proliferation of splenocytes it did not affect cell viability measured by MTT test (Gao et al., 2004). In our hands $50 \mu \mathrm{M}$ curcumin decreased proliferating cell viability to $40 \%$ already at $8 \mathrm{~h}$ as measured by MTT test. Also in a lower concentration, namely $25 \mu \mathrm{M}$, curcumin was harmful to normal $\mathrm{T}$ cells (not shown).

It is believed that the side effects of anticancer therapy affect mainly proliferating cells. Indeed, previously (Radziszewska et al., 1999) and in this paper we showed that UVC, which is a known DNA damaging agent, did not affect quiescent $\mathrm{T}$ cells, but induced apoptosis in proliferating ones. In contrast to UVC, curcumin induces cell death not only in proliferating but also in quiescent CD8+ cells, however, in a short-time treatment proliferating cells seem more sensitive to curcumin than quiescent ones. Moreover, the cell death mode induced by curcumin is distinct from that attributable to classical apoptosis whose main hallmark is oligonucleosomal DNA fragmentation resulting from caspase-3 activation.

Activation of caspase- 3 led to proteolysis of its specific substrates including DFF45/ICAD, the inhibitor of the major apoptotic nuclease DFF40/CAD. One would assume that the release of the nuclease from its inhibitor should result in DNA cleavage. However, DNA fragmentation was not observed in curcumin-treated cells. Essentially the same effect was observed earlier in Jurkat cells. We have some 
evidence that curcumin can inhibit DFF40/CAD by blocking magnesium binding in the active centre, thus preventing DNA fragmentation but not affecting cell death itself (Sikora et al., 2006).

Curcumin is a very promising chemopreventive agent. It can be administered safely to patients at doses of up to $180 \mathrm{mg}$ according to Sharma et al. (2001) and up to $8000 \mathrm{mg}$ daily according to Cheng et al. (2001). However, curcumin has low oral bioavailability in humans and may undergo intestinal metabolism. At doses of 36-180 mg daily given for up to 4 months neither curcumin nor its metabolites were detected in blood or urine (Sharma et al., 2001). Nonetheless, considering curcumin or curcumin derivatives' future use in the clinic and eventual intravenous application adverse side-effects could be expected such as death of $\mathrm{T}$ cells, including CD8+, and impairment of immune functions, e.g., suppression of proliferation, IL-2 production and decreased cytotoxicity of T cells (Gao et al., 2004). Taking into account the role of CD8+ cells in tumor response, their depletion during chemotherapy could be particularly undesirable.

\section{REFERENCES}

Akbar AN, Salmon M (1997) Cellular environments and apoptosis: tissue microenvironments control activated T-cell death. Immunol Today 18: 72-76.

Balasubramanyam K, Varier RA, Altaf M, Swaminathan V, Siddappa NB, Ranga U, Kundu TK (2004) Curcumin, a novel p300/CREB-binding protein-specific inhibitor of acetyltransferase, represses the acetylation of histone/nonhistone proteins and histone acetyltransferasedependent chromatin transcription. J Biol Chem 279: 51163-51171.

Balogun E, Hoque M, Gong P, Killeen E, Green CJ, Foresti R, Alam J, Motterlini R (2003) Curcumin activates the haem oxygenase-1 gene via regulation of Nrf2 and the antioxidant-responsive element. Biochem J 371: 887-895.

Bharti AC, Shishodia S, Reuben JM, Weber D, Alexanian R, Raj-Vadhan S, Estrov Z, Talpaz M, Aggarwal BB (2004) Nuclear factor-kappaB and STAT3 are constitutively active in CD138+ cells derived from multiple myeloma patients, and suppression of these transcription factors leads to apoptosis. Blood 103: 3175-3184.

Bielak-Mijewska A, Piwocka K, Magalska A, Sikora E (2004) P-glycoprotein expression does not change the apoptotic pathway induced by curcumin in HL-60 cells. Cancer Chemother Pharmacol 53: 179-185.

Bielak-Zmijewska A, Koronkiewicz M, Skierski J, Piwocka K, Radziszewska E, Sikora E (2000) Effect of curcumin on the apoptosis of rodent and human nonproliferating and proliferating lymphoid cells. Nutr Cancer 38: 131-138.

Brzezinska A (2005) Does in vitro replicative senescence of human CD8+ cells reflect the phenotypic changes observed during in vivo ageing? Acta Biochim Polon 52: 931-935.

Brzezinska A, Magalska A, Sikora E (2003) Proliferation of CD8+ in culture of human T cells derived from peripheral blood of adult donors and cord blood of newborns. Mech Ageing Dev 124: 379-387.
Brzezinska A, Magalska A, Szybinska A, Sikora E (2004) Proliferation and apoptosis of human CD8(+)CD28(+) and CD8(+)CD28(-) lymphocytes during aging. Exp Gerontol 39: 539-544.

Cipriani B, Borsellino G, Knowles H, Tramonti D, Cavaliere F, Bernardi G, Battistini L, Brosnan CF (2001) Curcumin inhibits activation of $\mathrm{V} \gamma 9 \mathrm{~V} \Delta 2 \mathrm{~T}$ cells by phosphoantigens and induces apoptosis involving apoptosis-inducing factor and large scale DNA fragmentation. J Immunol 167: 3454-3462.

Cheng AL, Hsu CH, Lin JK, Hsu MM, Ho YF, Shen TS, Ko JY, Lin JT, Lin BR, Ming-Shiang W; et al (2001) Phase I clinical trial of curcumin, a chemopreventive agent, in patients with high-risk or pre-malignant lesions. Anticancer Res 21: 2895-2900.

Deeb D, Xu YX, Jiang H, Gao X, Janakiraman N, Chapman RA, Gautam SC (2003) Curcumin (diferuloyl-methane) enhances tumor necrosis factor-related apoptosis-inducing ligand-induced apoptosis in $\mathrm{LNCaP}$ prostate cancer cells. Mol Cancer Ther 2: 95-103.

Deeb D, Jiang H, Gao X, Hafner MS, Wong H, Divine G, Chapman RA, Dulchavsky SA, Gautam SC (2004) Curcumin sensitizes prostate cancer cells to tumor necrosis factor-related apoptosis-inducing ligand/Apo2L by inhibiting nuclear factor-kappaB through suppression of IkappaBalpha phosphorylation. Mol Cancer Ther 3: 803-812.

De Martinis M, Franceschi C, Monti D, Ginaldi L (2005) Inflamm-ageing and lifelong antigenic load as major determinants of ageing rate and longevity. FEBS Lett 579: 2035-2039.

Enari M, Sakahira H, Yokoyama H, Okawa K, Iwamatsu A, Nagata S (1998) A caspase-activated DNase that degrades DNA during apoptosis, and its inhibitor ICAD. Nature 391: 43-50.

Gao X, Kuo J, Jiang H, Deeb D, Liu Y, Divine G, Chapman RA, Dulchavsky SA, Gautam SC (2004) Immunomodulatory activity of curcumin: suppression of lymphocyte proliferation, development of cell-mediated cytotoxicity, and cytokine production in vitro. Biochem Pharmacol 68: 51-61.

Giordano A, Avantaggiati ML (1999) p300 and CBP: partners for life and death. J Cell Physiol 181: 218-230.

Goel A, Boland CR, Chauhan DP (2001) Specific inhibition of cyclooxygenase-2 (COX-2) expression by dietary curcumin in HT-29 human colon cancer cells. Cancer Lett 172: 111-118.

Halenbeck R, MacDonald H, Roulston A, Chen TT, Conroy L, Williams LT (1998) CPAN, a human nuclease regulated by the caspase-sensitive inhibitor DFF45. Curr Biol 8: 537-540.

Hasbold J, Gett AV, Rush JS, Deenick E, Avery D, Jun J, Hodgkin PD (1999) Quantitative analysis of lymphocyte differentiation and proliferation in vitro using carboxyfluorescein diacetate succinimidyl ester. Immunol Cell Biol 77: 516-522.

Heath WR, Carbone FR (2001) Cross-presentation in viral immunity and self-tolerance. Nat Rev Immunol 1: 126134.

Hsu CH, Chuang SE, Hergenhahn M, Kuo ML, Lin JK, Hsieh CY, Cheng AL (2002) Pre-clinical and earlyphase clinical studies of curcumin as chemopreventive agent for endemic cancers in Taiwan. Gan To Kagaku Ryoho 29 (Suppl 1): 194-200.

Iqbal M, Sharma SD, Okazaki Y, Fujisawa M, Okada S (2003) Dietary supplementation of curcumin enhances antioxidant and phase II metabolizing enzymes in ddY male mice: possible role in protection against chemical carcinogenesis and toxicity. Pharmacol Toxicol 92: 33-38. 
Jacobson MD, Weil M, Raff MC (1997) Programmed cell death in animal development. Cell 88: 347-354.

Jiang MC, Yang-Yen HF, Yen JJ, Lin JK (1996) Curcumin induces apoptosis in immortalized NIH 3T3 and malignant cancer cell lines. Nutr Cancer 26: 111-120.

Karunagaran D, Rashmi R, Kumar TR (2005) Induction of apoptosis by curcumin and its implications for cancer therapy. Curr Cancer Drug Targets 5: 117-129.

Krammer PH (2000) CD95's deadly mission in the immune system. Nature 407: 789-795.

Leu TH, Su SL, Chuang YC, Maa MC (2003) Direct inhibitory effect of curcumin on Src and focal adhesion kinase activity. Biochem Pharmacol 66: 2323-2331.

Lin JK, Pan MH, Lin-Shiau SY (2000) Recent studies on the biofunctions and biotransformations of curcumin. Biofactors 13: 153-158.

Liu X, Li P, Widlak P, Zou H, Luo X, Garrard WT, Wang $X$ (1998) The 40-kDa subunit of DNA fragmentation factor induces DNA fragmentation and chromatin condensation during apoptosis. Proc Natl Acad Sci USA 95: 8461-8466.

Liu X, Zou H, Widlak P, Garrard W, Wang X (1999) Activation of the apoptotic endonuclease DFF40 (caspaseactivated DNase or nuclease). Oligomerization and direct interaction with histone H1. J Biol Chem 274: 13836-13840.

Mackall CL (2000) T-cell immunodeficiency following cytotoxic antineoplastic therapy: a review. Stem Cells 18: 10-18.

Manson MM, Farmer PB, Gescher A, Steward WP (2005) Innovative agents in cancer prevention. Recent Results Cancer Res 166: 257-275.

Nowak AK, Lake RA, Marzo AL, Scott B, Heath WR, Collins EJ, Frelinger JA, Robinson BW (2003) Induction of tumor cell apoptosis in vivo increases tumor antigen cross-presentation, cross-priming rather than cross-tolerizing host tumor-specific CD8 T cells. J Immunol 170: 4905-4913.

Piwocka K, Zablocki K, Wieckowski MR, Skierski J, Feiga I, Szopa J, Drela N, Wojtczak L, Sikora E (1999) A novel apoptosis-like pathway, independent of mitochondria and caspases, induced by curcumin in human lymphoblastoid T (Jurkat) cells. Exp Cell Res 249: 299-307.

Radziszewska E, Piwocka K, Skierski J, Sikora E (1999) UVC-induced cell death of IL-2-dependent human lymphocytes. Cell Biol Int 23: 97-103.

Radziszewska E, Piwocka K, Bielak-Zmijewska A, Skierski J, Sikora E (2000) Effect of aging on UVC-induced apoptosis of rat splenocytes. Acta Biochim Polon 47: 339-347.

Riedl SJ, Shi Y (2004) Molecular mechanisms of caspase regulation during apoptosis. Nat Rev Mol Cell Biol 5: 897-907.

Sharma RA, McLelland HR, Hill KA, Ireson CR, Euden SA, Manson MM, Pirmohamed M, Marnett LJ, Gescher AJ, Steward WP (2001) Pharmacodynamic and pharmacokinetic study of oral Curcuma extract in patients with colorectal cancer. Clin Cancer Res 7: 1894-1900.

Sharma RA, Euden SA, Platton SL, Cooke DN, Shafayat A, Hewitt HR, Marczylo TH, Morgan B, Hemingway D, Plummer SM, et al. (2004) Phase I clinical trial of oral curcumin: biomarkers of systemic activity and compliance. Clin Cancer Res 10: 6847-6854.

Shishodia S, Potdar P, Gairola CG, Aggarwal BB (2003) Curcumin (diferuloylmethane) down-regulates cigarette smoke-induced NF- $\kappa \mathrm{B}$ activation through inhibition of IkappaBalpha kinase in human lung epithelial cells: correlation with suppression of COX-2, MMP-9 and cyclin D1. Carcinogenesis 24: 1269-1279.

Sikora E, Bielak-Zmijewska A, Piwocka K, Skierski J, Radziszewska E (1997) Inhibition of proliferation and apoptosis of human and rat T lymphocytes by curcumin, a curry pigment. Biochem Pharmacol 54: 899-907.

Sikora E, Bielak-Zmijewska A, Magalska A, Piwocka K, Mosieniak G, Kalinowska M, Widlak P, Cymerman IA, Bujnicki JM (2006) Curcumin induces caspase-3 dependent apoptotic pathway but inhibits DFF40/CAD nuclease in human Jurkat cells. Mol Cancer Ther 5: 927934.

Widlak P, Garrard WT (2005) Discovery, regulation, and action of the major apoptotic nucleases DFF40/CAD and endonuclease G. J Cell Biochem 94: 1078-1087.

Widlak P, Lanuszewska J, Cary RB, Garrard WT (2003) Subunit structures and stoichiometries of human DNA fragmentation factor proteins before and after induction of apoptosis. J Biol Chem 278: 26915-26922.

Woo EJ, Kim YG, Kim MS, Han WD, Shin S, Robinson H, Park SY, Oh BH (2004) Structural mechanism for inactivation and activation of CAD/DFF40 in the apoptotic pathway. Mol Cell 14: 531-539.

Wyllie AH, Kerr JF, Currie AR (1980) Cell death: the significance of apoptosis. Int Rev Cytol 68: 251-306.

Zheng L, Tong Q, Wu C (2004) Growth-inhibitory effects of curcumin on ovary cancer cells and its mechanisms. J Huazhong Univ Sci Technolog Med Sci 24: 55-58. 